\title{
High diversity of genetic lineages and virulence genes in nasal Staphylococcus aureus isolates from donkeys destined to food consumption in Tunisia with predominance of the ruminant associated CC133 lineage
}

Haythem Gharsa', Rym Ben Sallem, Karim Ben Slama', Elena Gómez-Sanz², Carmen Lozano², Ahlem Jouini', Naouel Klibi ${ }^{1}$, Myriam Zarazaga ${ }^{2}$, Abdellatif Boudabous ${ }^{1}$ and Carmen Torres ${ }^{2 *}$

\begin{abstract}
Background: The objective of this study was to determine the genetic lineages and the incidence of antibiotic resistance and virulence determinants of nasal Staphylococcus aureus isolates of healthy donkeys destined to food consumption in Tunisia.

Results: Nasal swabs of 100 donkeys obtained in a large slaughterhouse in 2010 were inoculated in specific media for S. aureus and methicillin-resistant S. aureus (MRSA) recovery. S. aureus was obtained in 50\% of the samples, being all of isolates methicillin-susceptible (MSSA). Genetic lineages, toxin gene profile, and antibiotic resistance mechanisms were determined in recovered isolates. Twenty-five different spa-types were detected among the 50 MSSA with 9 novel spa-types. S. aureus isolates were ascribed to agr type I (37 isolates), III (7), II (4), and IV (2). Sixteen different sequence-types (STs) were revealed by MLST, with seven new ones. STs belonging to clonal clomplex CC133 were majority. The gene tst was detected in 6 isolates and the gene etb in one isolate. Different combinations of enterotoxin, leukocidin and haemolysin genes were identified among S. aureus isolates. The egc-cluster-like and an incomplete egc-cluster-like were detected. Isolates resistant to penicillin, erythromycin, fusidic acid, streptomycin, ciprofloxacin, clindamycin, tetracycline, or chloramphenicol were found and the genes blaZ, erm(A), erm(C), tet(M), fusC were identified.

Conclusions: The nares of donkeys frequently harbor MSSA. They could be reservoirs of the ruminant-associated CC133 lineage and of toxin genes encoding TSST-1 and other virulence traits with potential implications in public health. CC133 seems to have a broader host distribution than expected.
\end{abstract}

Keywords: Staphylococcus aureus, Donkey, spa types, CC133, Virulence genes, Tunisia

\footnotetext{
* Correspondence: carmen.torres@unirioja.es

${ }^{2}$ Departamento de Agricultura y Alimentación, Área de Bioquímica y Biología Molecular, Universidad de La Rioja, Madre de Dios 51, Logroño 26006, Spain Full list of author information is available at the end of the article
} 


\section{Background}

Staphylococcus aureus is a global problem for both humans and animals that affect hospitalized patients and also healthy individuals in the community. This microorganism is usually associated with skin and soft tissue infections. However, it is also able to cause serious diseases, such as pneumonia, meningitis, or septicaemia, among others. Additionally, the pathogenicity of $S$. aureus infections is facilitated by the expression of several virulence factors, which include cell wall-associated adhesins and several toxin groups [1,2]. The coordinated expression of these virulence factors is dependent on a global quorum-sensing regulator system, named agr (accessory gene regulator) [3]. Methicillin-resistant $S$. aureus (MRSA) is a well-recognized human pathogen that has also been identified as a veterinary and zoonotic pathogen. MRSA can cause animal infections and is also able to colonize the skin, nasal and oral mucosa of healthy animals. Several studies have reported the emergence of MRSA among farm animals [4-7]. Moreover, the emergence of MRSA in the equine population has been demonstrated [8-10] and, very recently, MRSA isolates have been detected in microbiota of healthy donkeys [11].

More than forty-four million donkeys do exist on our planet, of which 40 million (96\%) inhabit in developing countries [12] where donkeys play an important role serving as draught animals (packing, carting, threshing, farm cultivation, riding) [12], as well as for feeding; this is the case of milk [13] or meat products [14]. In Tunisia, there are over a hundred twenty three thousand donkeys (http://www.onagri.tn), what represents over $65.5 \%$ of the total equine population and it is considered one of the countries with the largest number of donkeys [15,16]. Donkey food represents approximately $5 \%$ of total meat consumed in Tunisia and it is especially eaten in low income families (http://www.femmezoom.com/).

Few data do exist about the genetic lineages of $S$. aureus and the prevalence of MRSA that colonizes nares of healthy equids. So far, different clonal lineages such as CC8, CC22 or CC398 have been identified in horses $[10,17]$. Moreover, the isolates detected presented varied susceptibility to antimicrobials, different toxin profiles and diverse agr and SCCmec types depending on the clone found $[10,17]$. Remarkably, no tst and lukF/lukSPV positive isolates have been detected in these animals; additionally, as far as we know, no previous studies of this type have been performed in Tunisia and there are very few reports in other African countries [12].

The objectives of this work were to analyse the prevalence of $S$. aureus in nasal samples of healthy donkeys destined for food consumption in Tunisia and to determine the genetic lineages and the presence of antimicrobial resistance and virulence genes in the recovered isolates.

\section{Methods}

\section{Sampling and microbiological isolation}

Nasal swabs from 100 healthy donkeys were obtained during March-May 2010 in a large slaughterhouse that receives animals destined for human consumption from farms of all Tunisia. The director of the abattoir gave his permission for taking the samples and it was supervised by the veterinarians of the abattoir. The ARRIVE (Animal Research: reporting of in vivo experiments) guidelines were followed in this study.

Nasal swabs were incubated in Tryptone Soy Broth (TSB) for $48 \mathrm{~h}$ and then subcultured on Baird-Parker agar (BP) and ORSAB medium (Oxacillin Resistance Screening Agar Base, Oxoid) for 24-48 hours for S. aureus and MRSA recovery, respectively. Suspected S. aureus colonies were initially identified by conventional methods [Gram-staining, catalase test, oxidase test, DNase production, and ability to coagulate rabbit plasma (BioRad)]. S. aureus identification was confirmed by amplification of the species-specific nuc gene and, although all isolates were susceptible to methicillin, the presence of the $m e c A$ gene was also tested [5].

\section{Antimicrobial susceptibility testing}

Susceptibility to 17 antimicrobial agents was performed using the disk-diffusion method [18]. Antimicrobial agents tested were (charge in $\mu \mathrm{g} /$ disk): penicillin 10 units, oxacillin (1), cefoxitin (30), kanamycin (30), gentamicin (10), tobramycin (10), tetracycline (30), chloramphenicol (30), trimethoprim-sulfamethoxazole (1.25/ 23.75), erythromycin (15), amikacin (30), ciprofloxacin (5), mupirocin (5), vancomycin (30), and teicoplanin (30). In addition, susceptibility to fusidic acid (10) and streptomycin (10 units) was carried out for which methods and breakpoints employed were those recommended by the Société Française de Microbiologie (http://www.sfm.asso.fr).

\section{Detection of antimicrobial resistance genes}

The ribosomal methylases encoded by erm(A), erm(B) and $\operatorname{erm}(\mathrm{C})$ genes, which confer resistance to erythromycin and clindamycin, and the efflux pump encoded by $m s r(\mathrm{~A})$ gene, conferring resistance to erythromycin, were studied by PCR in erythromycin-resistant isolates with primers and conditions as previously described [5]. In addition, tet $(\mathrm{K})$, tet $(\mathrm{M})$ and $\operatorname{tet}(\mathrm{L})$ genes, which confer resistance to tetracycline, blaZ gene to penicillin, fus B and fusC genes to fusidic acid, ant(6)-Ia, str and ant(3)(9)' genes to streptomycin, and $c a t_{p C 221}, c a t_{p C 223}$, and $c a t_{p C 194}$ genes to chloramphenicol were studied by PCR in antimicrobial-resistant S. aureus isolates [4]. 
Mutations in elongation factor $\mathrm{G}$ were studied by sequence analysis of fus A gene in all fusidic acid-resistant isolates [19].

\section{Molecular typing of $S$. aureus isolates}

Spa-typing was performed in all $S$. aureus isolates as described elsewhere [20]. The polymorphic $\mathrm{X}$ region of spa gene was amplified by PCR, and sequences were analyzed using Ridom Staph-Type software version 1.5.21 (Ridom $\mathrm{GmbH}$ ), which automatically detects spa repeats and assigns a spa-type according to http://spaserver. ridom.de/. Identification of agr allele group (I-IV) was determined by PCR as earlier described [21].

Multilocus-sequence-typing (MLST) was performed in selected $S$. aureus isolates (one isolate of each detected spa-type): the allelic profile of each isolate was obtained by sequencing internal fragments of 7 unlinked housekeeping genes $(\operatorname{arcC}$, aroE, glpF, gmk, pta, tpi, and yqiL), allowing the determination of the sequence-type (ST), by the MLST database (http://saureus.mlst.net/). In these selected isolates, the clonal complexes (CC) were assigned according to the obtained ST; in the remaining isolates, the $\mathrm{CC}$ were assumed depending on the spa-types.

All isolates that presented spa-types associated with the clonal complex $\mathrm{CC} 133$ were tested for their capacity to coagulate bovine plasma (Sigma-Aldrich) following standard methodology [22].

\section{Detection of staphylococcal toxin genes}

All isolates were tested by PCR for the presence of 18 genes coding for staphylococcal enterotoxins (sea, seb, sec, sed, see, seg, seh, sei, sej, sek, sel, sem, sen, seo, sep, seq, ser and seu), tst gene encoding the TSST-1 (Toxic Shock Syndrome Toxin) [23], lukF/lukS-PV genes encoding leukocidin PVL (Panton Valentine leukocidin), lukED genes encoding the bicomponent leukotoxin LukE-LukD, lukM gene coding for leukocidin $\mathrm{M}$ as well as eta and etb genes encoding exfoliative ETA and ETB toxins, respectively, and $h l a, h l b, h l d, h l g$ and $h l g$ genes encoding haemolysin toxins. The presence of all these genes were tested using primers and conditions as previously described [24].

\section{Results}

\section{Field survey for S. aureus isolates from donkeys}

No MRSA isolates were recovered in the 100 nasal samples of donkeys tested in this study when inoculated onto ORSAB plates. Nevertheless, $S$. aureus isolates were obtained from Baird-Parker agar plates in 50 of the 100 tested samples (50\%), and one isolate per sample was further studied. The collection of $50 \mathrm{~S}$. aureus isolates were cefoxitin and oxacillin susceptible, lacked the mecA gene, and then were confirmed methicillinsusceptible $S$. aureus (MSSA).

\section{Molecular typing of MSSA isolates detected in this study} The characteristics of the 50 MSSA isolates recovered in this study are shown in Table 1. Twenty-five different spa-types were detected, with nine of them being new and registered in the web site (http://spa.ridom.de/ submission.shtml) as (number of isolates): t8449 (1), t8842 (1), t8840 (1), t8837 (1), t8836 (1), t7721 (1), t7720 (1), t7718 (2) and t7717 (2). The already described spa-types detected among our isolates were as follows (number of isolates when more than one): t1166 (14), t127 (4), t166 (4), t701 (4), t2484 (2), t091, t593, t1403, t1736, t1784, t2420, t3043, t3583, t3896, t4735, and t4781.

Twenty-five MSSA isolates were typed by MLST (one isolate of each spa-type) and 16 different STs were identified, seven of them being new and registered as ST2109, ST2110, ST2111, ST2150, ST2151, ST2152 and ST2181 (Table 1). Two isolates showing new spa-types also presented new STs (ST2111-t8837 and ST2152t8842). The STs or spa-types detected among our S. aureus isolates were found to be distributed within eight clonal complexes (\% of the isolates): CC133 (44\%), CC1 (14\%), CC6 (10\%), CC522 (8\%), CC72 (6\%), CC7 (2\%), CC15 (2\%), and CC22 (2\%). The remaining detected STs (10\% of the isolates) did not belong to any $\mathrm{CC}$ representing singletons. The new detected STs belonged to CC133 (2 isolates), CC7, and CC22, whereas three STs were singletons. All strains which presented spa-types associated with $\mathrm{CC} 133$ presented the ability to coagulate bovine plasma.

Amplification of the agr locus showed that agr group I was predominant (detected in 37 of 50 MSSA isolates, $74 \%$ ), the remaining isolates being ascribed to agr group III (detected in 7 isolates, 14\%), agr group II (4 isolates, $8 \%$ ), and agr group IV (2 isolates, $4 \%$ ).

\section{Characterization of antimicrobial resistance mechanisms and virulence genes}

Sixty percent of $S$. aureus isolates showed susceptibility to all tested antimicrobial agents, while the remaining isolates revealed resistance to the following antimicrobials: penicillin (24\% of isolates, carrying blaZ gene), erythromycin [16\%, carrying $\operatorname{erm}(\mathrm{A})$ (8 isolates) and erm(A) + $\operatorname{erm}(\mathrm{C})$ (2 isolates)], tetracycline [2\%, carrying tet $(\mathrm{M})$ gene], and fusidic acid (24\%, one strain carrying fusC gene). All 50 MSSA isolates showed susceptibility to amikacin, cefoxitine, ciprofloxacin, gentamicin, kanamycin, mupirocin, oxacillin, streptomycin, teicoplanin, tobramycin, trimethoprim-sulfamethoxazole, and vancomycin. No mutations in elongation factor $\mathrm{G}$ of fusA gene were detected in analyzed fusidic acid-resistant isolates. 
Table 1 Phenotypic and genotypic characteristics of the $\mathbf{5 0}$ methicillin-susceptible S. aureus isolates recovered from healthy donkeys in Tunisia

\begin{tabular}{|c|c|c|c|c|c|c|c|c|}
\hline $\begin{array}{l}\text { Number of } \\
\text { isolates }\end{array}$ & $\begin{array}{l}\text { spa } \\
\text { type }^{a}\end{array}$ & $\mathrm{MLST}^{\mathrm{a}} \mathrm{b}$ & $C C^{b}$ & $\begin{array}{l}\text { agr } \\
\text { type }\end{array}$ & $\begin{array}{l}\text { enterotoxin genes } \\
\text { detected }^{c d}\end{array}$ & $\begin{array}{l}\text { Other toxin genes } \\
\text { detected }^{c}\end{array}$ & $\begin{array}{l}\text { Phenotype of antibiotic } \\
\text { resistance }^{c, e}\end{array}$ & $\begin{array}{l}\text { Resistance genes } \\
\text { detected }^{c}\end{array}$ \\
\hline$\overline{14}$ & $\mathrm{t} 1166$ & ST133 & CC133 & 1 & $\operatorname{see}^{1}, \operatorname{sei}^{1}, \operatorname{ser}^{10}$ & hla, hlb ${ }^{11}$, hld, lukED & $E^{2}-F A^{3}$ & $\operatorname{erm}(A)^{2}$ \\
\hline 2 & t7718 & ST133 & CC133 & I & $\mathrm{see}^{1}$, ser & hla, hld, lukED & & \\
\hline 1 & $\mathrm{t} 2420$ & ST133 & CC133 & 1 & seq, ser & hla, hld, lukED & $\mathrm{E}-\mathrm{FA}$ & $\operatorname{erm}(\mathrm{A})$ \\
\hline 1 & $\mathrm{t} 1403$ & ST133 & CC133 & 1 & ser & hla, hlb, hld, lukED & P-E-S-FA & blaz, erm(A) \\
\hline 1 & t8836 & ST133 & CC133 & I & & hla, hlb, hld, lukED & & \\
\hline 1 & t3583 & ST133 & CC133 & 1 & seh & hla, hlb, hld, lukED & & \\
\hline 1 & $\mathrm{t} 4735$ & ST2150 & CC133 & I & ser & hla, hlb, hld, lukED & & \\
\hline 1 & t8837 & ST2111 & CC133 & 1 & sei, ser & hla, hlb, hld, lukED & & \\
\hline 4 & $\mathrm{t} 127$ & ST1738 & CC1 & III & $\begin{array}{l}\text { sea }^{1}, \text { seb }^{1}, \text { see }^{1}, \text { sek }^{1}, \text { seh, } \\
\text { sea }^{1}, \text { ser }^{3}\end{array}$ & tst $^{1}$, hla, hlb, hld, lukED, & $P^{2}-F A^{1}$ & blaZ $^{2}$, fus $C^{1}$ \\
\hline 1 & $\mathrm{t} 1784$ & ST1 & CC1 & III & seh, ser & hla,hlb, hld lukED & & \\
\hline 1 & t7720 & ST1 & CC1 & III & seh, ser & hla, hld, lukED & P-E-CP-FA & blaZ, erm(A) \\
\hline 1 & t3896 & ST1 & $\mathrm{CC} 1$ & III & sea, see, seh, sek, sea & hla, hld, lukED & P-FA & blaz \\
\hline 4 & t701 & ST6 & CC6 & I & $\operatorname{sea}^{3}, \operatorname{see}^{2}, \operatorname{sed}^{2}, \operatorname{ser}^{3}$ & tst', hla, hlb ${ }^{1}, h l d$, lukED & $P-E^{1}-S^{1}-F A^{1}$ & $\begin{array}{l}\text { blaZ, erm }(A)^{1} \\
\operatorname{erm}(C)^{1}\end{array}$ \\
\hline 1 & t8840 & ST6 & CC6 & 1 & seh, seq, ser & hla, hlb, hld, lukED & $P$ & blaz \\
\hline 4 & $\mathrm{t} 166$ & ST2057 & CC522 & I & $\sec ^{1}, \operatorname{sej}^{2}, \mathrm{sel}^{1}, \mathrm{ser}^{2}$ & $\begin{array}{l}\text { tst' }{ }^{1} \text { hla, hlb, hld, lukED, } \\
\text { lukM }\end{array}$ & $E^{3}-C^{1}-F A^{3}$ & $\operatorname{erm}(A)^{3}, \operatorname{erm}(C)^{1}$ \\
\hline 2 & t7717 & ST72 & CC72 & I & $\begin{array}{l}\text { [seg, sei, sem, sem, seo, } \\
\text { seu }]^{1}, \text { see }^{1}, \text { sel }\end{array}$ & hla, hlb, hld, lukED & & \\
\hline 1 & $\mathrm{t} 7721$ & ST72 & CC72 & I & $\begin{array}{l}\text { [seg, sei, sem, sem, seo, } \\
\text { seu], sec, sel }\end{array}$ & hla, hld, lukED & & \\
\hline 1 & t091 & ST2110 & CC7 & 1 & ser & hla, hld, lukED & P-TE-CP & blaZ, tet(M) \\
\hline 1 & t593 & ST15 & CC15 & $\|$ & ser & hla, hld, lukED & & \\
\hline 1 & $\mathrm{t} 4781$ & ST2181 & CC22 & I & $\begin{array}{l}\text { [seg, sei, sem, sem, } \\
\text { seo, seu], ser }\end{array}$ & tst, hla, hld, hlg & $P$ & blaz \\
\hline 2 & $\mathrm{t} 2484$ & ST2151 & Singleton & $\|$ & $\begin{array}{l}\text { [sem, sen, sei, seu }]^{1}, \text { sec, } \\
\text { sel, sem }^{1}\end{array}$ & tst ${ }^{1}$, hla, hlb, hld & & \\
\hline 1 & $\mathrm{t} 1736$ & ST2109 & Singleton & IV & {$[$ sem, sen, sei $]$} & hla, hlb, hld, lukED & & \\
\hline 1 & t3043 & ST1660 & Singleton & $\|$ & $\begin{array}{l}\text { [sem, sen, sei, seu], } \\
\text { sec, sel, ser }\end{array}$ & tst, hla, hlb, hld & $E$ & $\operatorname{erm}(A)$ \\
\hline 1 & t8449 & ST350 & Singleton & 1 & {$[$ sem, sen, sei, seu $]$} & hla, hlb, hld & & \\
\hline 1 & t8842 & ST2152 & Singleton & IV & sej & etb, hla, hlb, hld, lukED & & \\
\hline
\end{tabular}

a New spa-types or sequence types detected are shown in bold.

${ }^{\mathrm{b}}$ The MLST was performed in one isolate of each spa-type and the corresponding ST and CC were assumed for all isolates presenting the same spa-type.

c In some cases, not all the isolates of the group presented the indicated characteristics (genes or phenotype). Whenever happened, the number of isolates with this characteristic is indicated in superscript.

${ }^{\mathrm{d}}$ Genes normally physically linked that compound the different egc clusters are included in brackets.

e P: penicillin; E: erythromycin; TE: tetracycline; S: streptomycin; CP: ciprofloxacin; C: chloramphenicol; FA: fusidic acid.

Six MSSA isolates carried the gene tst encoding TSST-1 (12\%). The gene $e t b$ encoding toxin ETB was detected in one isolate (2\%). None of our isolates harbored the genes for PVL or ETA toxins. Other virulence genes carried by MSSA isolates were: hla, hld (100\%), lukED (90\%), hlb (70\%), ser (60\%), sei (20\%), seh (18\%), sen (16\%), see, sem, seu (14\%), sel (12\%), sea, sec (10\%), lukM, seq (8\%), seg, sej, seo (6\%), sed, sek (4\%), seb, $h l g, h l g_{v}(2 \%)$ and the egc cluster-like [sei, seg, sem, sen, seo, seu](6\%) (Table 1).

\section{Discussion}

Very limited data on the nasal carriage of S. aureus in donkeys are available. In this sense, a study conducted in Ethiopia described the detection of $S$. aureus in the upper respiratory tract of $13 \%$ of tested donkeys [12]. Other study performed in Italy detected S. aureus in 6\% of donkey milk samples [13]. The high recovery rate of S. aureus detected among nasal samples of healthy donkeys in the present report (50\% of tested samples) is relevant, and represents the first study of this type in 
Tunisia. The high diversity of genetic lineages among the $S$. aureus recovered is noteworthy. However, it should be noted that all our strains were methicillin susceptible. Elevated clonal variety has been already detected in other studies among MSSA strains and it seems that MSSA of human show a higher genetic diversity than MRSA [25].

The 16 different STs identified by MLST among $S$. aureus isolates, with seven of them new, were distributed in eight clonal complexes (CC133, CC1, CC6, CC522, CC72, CC7, CC15 and CC22), and five singletons. Among these, $\mathrm{CC} 133, \mathrm{CC} 1$ and $\mathrm{CC} 6$ were predominant and grouped $68 \%$ of typed isolates.

Twenty two of our isolates (44\%) corresponded to the major ruminant lineage $\mathrm{CC} 133[6,22]$, being the major detected lineage. Several previous studies have reported the existence of CC133 in clinical S. aureus isolates of cattle, goats and sheep [26-28]; nevertheless, this clone was not detected in an earlier study carried out in $\mathrm{Tu}$ nisia on healthy sheep [29]. It is interesting to remark that the clonal complex CC133 was associated with different spa-types in donkey isolates in our study (t1166, t1403, t2420, t3583, t7718, t8836) or in sheep and goat isolates (t544, t2678, t3495, t4560, t5592, t7294, t7296, t7297, t7298, t7300) in previous studies [28]. It has been reported that $S$. aureus isolates of the clonal complex CC133 have been also responsible for most cases of mastitis in dairy farms [30], and it seems that this clone may have a broad geographic distribution. The agr-type I detected among the CC133 isolates in our study was coincident with former reports [31]. Some authors propose that strains of lineage CC133 could have evolved and adapted to small ruminants derived from humans due to an adaptive genome diversification resulted from allelic variation, gene loss, and horizontal acquisition of mobile genetic elements containing virulence genes with attenuated or enhanced activity in ruminants. The capacity to coagulate bovine plasma detected in our isolates belonging to this $\mathrm{CC}$ is a characteristic previously reported for isolates adapted to small ruminants and bovine [22]; and the acquisition of a novel staphylococcal pathogenicity island (SaPIov2) carrying a novel von Willebrand factor-binding protein (vWBP) with ruminant-specific coagulase activity has been described among isolates of this lineage [22]. On the other hand, a very recent study undergone in a Danish Zoo [32] has revealed that ST133 may have a broader host distribution since it was detected in S. aureus of a wide variety of animal species. However, to the best of our knowledge, this is the first description of this genetic lineage in donkeys [6].

Seven MSSA isolates were ascribed to the clonal complex CC1 (those of ST1 and ST1738) which is a common lineage among human isolates [26]. This data is in accordance with earlier reports [33] where $S$. aureus isolated from equines were more likely to cluster into human associated lineages. In the referred study performed in United Kingdom, equine-associated S. aureus isolates were assigned to the major human lineage CC1. Although this CC seems to be related to human isolates, a possible animal origin has also been suggested in other studies, given that its presence in other animal species is not exceptional [34].

The lineage CC6, less frequently detected among our isolates (5 isolates), has been previously detected in both human and animal S. aureus isolates [35,36]. Our CC6 MSSA isolates were classified into the agr group I, which is in harmony with previous studies [37].

Three MSSA isolates were ascribed to the clonal complex CC72; this clone has been detected in humans in different countries $[38,39]$. One isolate belonged to the clonal complex $\mathrm{CC} 15$, which has been before detected in humans at both community and hospital settings $[40,41]$. Another study conducted in five African countries [42] showed that $12 \%$ of $S$. aureus obtained from humans in the community corresponded to the $\mathrm{CC} 15$ clone. In our study, the characteristics of our CC15 isolate were different from other previous reports in relation to the spa-types, agr-types and virulence determinants [40,42].

One MSSA isolate was ascribed to lineage CC22, associated to the United Kingdom EMRSA-15, which is commonly isolated from pet animals, especially dogs $[35,43]$. This result is consistent with that of [17] where the MRSA isolates of equines belonged to the same clone EMRSA-15 (CC22) and harbored the egc clusterlike comprising the enterotoxin genes: seg, sei, sem, sen, seo, and seu [37].

Several virulence genes were detected in our MSSA isolates. The detection of the tst gene in $12 \%$ of isolates is interesting, although this percentage was lower than the one detected among $S$. aureus isolates from healthy sheep $(78 \%)$ or healthy humans $(20 \%)$ in Tunisia $[29,44]$. Nevertheless, the tst gene was not detected among $S$. aureus isolates of donkey milk in a previous report [13]. Most of our MSSA isolates harboured haemolysin genes, where the hla and hld genes were present in all our isolates. Similarly, a significant number of strains harboured the $h l b$ gene, while the $h l g$ and $h l g$ venes were only present in one isolate. High occurrence of the hld gene in nasal $S$. aureus isolates of healthy sheep in Tunisia has also been reported [29]. Remarkably, most of our isolates (90\%) carried the lukED genes, which are commonly present in cattle causing bovine mastitis infections [5]. In addition, a high number of enterotoxin genes, with 3 distinct egc-cluster-like variants, were observed. With this regard, some strains presented some but not all of the genes comprising the 
$e g c$-cluster or $e g c$-cluster-like. The absence of one or more genes in the egc-cluster has been previously reported $[45,46]$. Even though $S$. aureus associated food poisoning outbreaks are normally due to human isolates [47], the presence of a wide variety of enterotoxin genes in $S$. aureus from donkey reflects the adaptation of enterotoxigenic strains to different mammalian species. The presence of the exfoliatin $e t b$ gene in one isolate, which also revealed novel genetic characteristics (t8842ST2152), is remarkable.

Most of our MSSA showed susceptibility to the antimicrobials tested (60\%) with several exceptions. The low frequency of penicillin resistance detected among our isolates contrasts with the high frequency of this type of resistance reported for human isolates, even in commensal strains $[44,45]$; however, it is in agreement with isolates of sheep origin [29]. With regard to fusidic acid resistance, the rate found in different countries is very variable, with percentages ranging from $<1 \%$ to $>50 \%$ [48]. No mutations in elongation factor $G$ have been detected in the fus A sequences of the analyzed fusidic acid resistant $S$. aureus isolates and the fus $C$ gene was only detected in one strain. The resistance mechanism of the remaining fusidic acid resistant MSSA strains of this study remains unknown. In addition, 2 streptomycin- and one chloramphenicol-resistant isolates did not present any of the tested resistance genes.

\section{Conclusions}

In conclusion, the nares of healthy donkeys could be a reservoir of $S$. aureus isolates of the small ruminant associated CC133 lineage and also of isolates carrying the toxic shock syndrome related gene tst and enterotoxin genes responsible for food poisoning outbreaks.

Remarkably, CC133 seems to have a broader host distribution having been detected in different animal species. More studies should be performed in the future to gain knowledge in the genetic lineages of S. aureus circulating among healthy animals, as well as in the capacity of these strains to produce virulence factors, due to the risk of animal-to-human bacterial transfer and the acquisition and dissemination of the SCCmec element, which is responsible for genetic background common to endemic methicillin resistant $S$. aureus.

\footnotetext{
Abbreviations

MRSA: Methicillin-resistant Staphylococcus aureus; MSSA: Methicillinsusceptible Staphylococcus aureus; MLST: Multilocus-sequence-typing; ST: Sequence type; CC: Clonal complex; TSST-1: Toxic Shock Syndrome Toxin; PVL: Panton valentine leukocidin; ORSAB: Oxacillin resistance screening agar base.

Part of the results of this manuscript has been presented in the 7th European Congress on Tropical Medicine and International Health in Barcelona, Spain $3^{\text {rd }}-6^{\text {th }}$ October 2011.
}

\section{Competing interests}

Non-financial competing interests do exist.

\section{Authors' contributions}

HG and RBS took the animal samples, isolated the S. aureus strains and identified them and carried out important part of the genetic analysis. They participated in the writing of the manuscript. KBS participated in the design of the study, writing of the paper and in the collection of samples and isolation of microorganisms. EGS and CL contributed to the genetic analysis of the virulence factors in the collection of isolates and in the revision of the paper. AJ and NK participated in the identification of S. aureus isolates and in the study of the resistance genes of the microorganisms. MZ contributed to the design of the study, the general discussion of the manuscript and the writing of the paper. $C T$ and $A B$ conceived the study, participated in its design and carried out the general coordination of it and helped to draft the manuscript. All authors read and approved the final manuscript.

\section{Authors' information}

EGS, CL, MZ and CT belong to the Research Group on -Antimicrobial resistance, virulence and molecular epidemiology in bacteria of animals, food, humans and the environment of the University of Rioja that is coordinated by CT (PhD in Pharmacy and professor of the University of Rioja) and with important contribution of $\mathrm{MZ}$ (PhD in Veterinary and Associate Prof. of the Univ. of Rioja). $H G, R B S, K B S, A J, N K$ and $A B$ belong to the research group on Surveillance of antimicrobial resistance and virulence in animals, food and the environment and implication in human health of the Univ. of Tunis (in Tunisia), coordinated by $A B$ (PhD in Biology and professor of that University).

\section{Acknowledgements}

This study has been possible thank to an Integrated Action financed by the Agencia Española de Cooperación Internacional al Desarrollo (AECID) from the Ministerio de Asuntos Exteriores of Spain (D/030439/10 y A1/038210/11) and from the Tunisian Ministry of Higher Education and Scientific Research. C. Lozano has a predoctoral fellowship from the Ministerio de Ciencia e Innovación of Spain, E. Gómez-Sanz a predoctoral fellowship from the Gobierno de La Rioja. We acknowledge the cooperation of the company Ellouhoum (Production and Marketing of the meat in Tunisia) for sample collection.

\section{Author details}

${ }^{1}$ Laboratoire des Microorganismes et Biomolécules Actives, Faculté des Sciences de Tunis, Université Tunis-El Manar, Tunis 2092, Tunisia.

2Departamento de Agricultura y Alimentación, Área de Bioquímica y Biología Molecular, Universidad de La Rioja, Madre de Dios 51, Logroño 26006, Spain.

Received: 31 May 2012 Accepted: 22 October 2012

Published: 29 October 2012

\section{References}

1. Dinges MM, Orwin PM, Schlievert PM: Exotoxins of Staphylococcus aureus. Clin Microbiol Rev 2000, 13:16-34.

2. Somerville GA, Proctor RA: At the crossroads of bacterial metabolism and virulence factor synthesis in Staphylococci. Microbiol Mol Biol Rev 2009, 73:233-248.

3. Kahl BC, Belling G, Becker, Chatterjee I, Wardecki K, Hilgert K, Cheung AL, Peters G, Herrmann M: Thymidine-dependent Staphylococcus aureus small-colony variants are associated with extensive alterations in regulator and virulence gene expression profiles. Infect Immun 2005, 73:4119-4126.

4. Vanderhaeghen W, Hermans K, Haesebrouck F, Butaye P: Methicillinresistant Staphylococcus aureus (MRSA) in food production animals. Epidemiol Infect 2010, 138:606-625.

5. Gómez-Sanz E, Torres C, Lozano C, Fernández-Pérez R, Aspiroz C, Ruiz-Larrea F, Zarazaga M: Detection, molecular characterization, and clonal diversity of methicillin-resistant Staphylococcus aureus CC398 and CC97 in Spanish slaughter pigs of different age groups. Food Pathog Dis 2010, 7:1269-1277.

6. Fitzgerald JR: Livestock-associated Staphylococcus aureus: origin, evolution and public health threat. Trends Microbiol 2012, 20:192-198.

7. Pantosti A: Methicillin-resistant Staphylococcus aureus associated with animals and its relevance to human health. Frontiers Microbiol 2012, 3:127. 
8. Weese JS, Duijkeren VE: Methicillin-resistant Staphylococcus aureus and Staphylococcus pseudintermedius in veterinary medicine. Vet Microbiol 2009, 140:418-429.

9. Burton S, Reid-Smith R, McClure JT, Weese JS: Staphylococcus aureus colonization in healthy horses in Atlantic Canada. Can Vet J 2008, 49:797-799.

10. Van den Eede A, Martens A, Lipinska U, Struelens M, Deplano A, Denis O, Haesebrouck F, Gasthuys F, Hermans K: High occurrence of methicillin-resistant Staphylococcus aureus ST398 in equine nasal samples. Vet Microbiol 2009, 133:138-144.

11. Foti M, Fisichella V, Giacopello C: Detection of methicillin-resistant Staphylococcus aureus (MRSA) in the microbial flora from the conjunctiva of healthy donkeys from Sicily (Italy). Vet Ophthalmol 2012, 1463-5224.

12. Gutema DF, Duguma BE, Dinka AG: Isolation and identification of aerobic bacterial flora from the upper respiratory tract of donkeys in Central Ethiopia. Int J Appl Res Vet Med 2009, 7:181-189.

13. Pilla R, Dapra V, Zecconi A, Piccinini R: Hygienic and health characteristics of donkey milk during a follow-up study. J Dairy Res 2010, 77:392-397.

14. Polidori P, Vincenzetti S, Cavallucci C, Beghelli D: Quality of donkey meat and carcass characteristics. Meat Sci 2008, 80:1222-1224.

15. Wilson RT: Distribution and importance of the domestic donkey in circumsaharan Africa. Sing J Trop Geog 1978, 2:136-143.

16. Nengomasha EM, Pearson RA, Wold AG: Empowering people through donkey power into the next millennium. Empowering Farmers with Animal Traction (Proceedings of an ATNESA Workshop) 2000, 21:22-31.

17. Walther B, Monecke S, Ruscher C, Friedrich AW, Ehricht R, Slickers P, Soba A, Wleklinski CG, Wieler LH, Lubke-Becker A: Comparative molecular analysis substantiates zoonotic potential of equine methicillin-resistant Staphylococcus aureus. J Clin Microbiol 2009, 47:704-710.

18. CLSI: Performance standards for antimicrobial susceptibility testing; eighteenth informational supplement. Wayne, Pennsylvania, USA: CLSI document M100-18 CLSI; 2010.

19. O'Neill AJ, Bostock M, Moita AM, Chopra I: Antimicrobial activity and mechanisms of resistance to cepahalosporin $\mathrm{P} 1$, an antibiotic related to fusidic acid. J Antimicrob Chemother 2002, 50:839-848.

20. Harmsen D, Claus H, Witte W, Rothganger J, Claus H, Turnwald D, Vogel U: Typing of methicillin-resistant Staphylococcus aureus in a university hospital setting by using novel software for spa repeat determination and database management. J Clin Microbiol 2003, 41:5442-5448.

21. Shopsin B, Herring S, Kreiswirth BN: Hospital-acquired and community-derived: the future of MRSA? Clin Infect Dis 2003, 37:151-152. author reply 152

22. Guinane CM, Ben Zakour NL, Tormo-Mas MA, Weinert LA, Lowder BV, Cartwright RA, Smyth DS, Smyth CJ, Lindsay JA, Gould KA, Witney A, Hindsb J, Bollback JP, Rambaut A, Penadés JR, Fitzgerald JR: Evolutionary genomics of Staphylococcus aureus reveals insights into the origin and molecular basis of ruminant host adaptation. Gen Biol Evol 2010, 2:454-466.

23. Hwang SY, Kim SH, Jang EJ, Kwon NH, Park YK, Koo HC, Jung WK, Kim JM, Park YH: Novel multiplex PCR for the detection of the Staphylococcus aureus superantigen and its application to raw meat isolates in Korea. Int J Food Microbiol 2007, 117:99-105.

24. Jarraud S, Mougel C, Thioulouse J, Lina G, Meugnier H, Forey F, Nesme X, Etienne J, Vandenesch F: Relationships between Staphylococcus aureus genetic background, virulence factors, agr groups (alleles), and human disease. Infect Immun 2002, 70:631-641.

25. Grundmann H, Aanensen DM, Van den Wijngaard CC, Spratt BG, Harmsen D, Friedrich AW, European Staphylococcal Reference Laboratory Working Group: Geographic distribution of Staphylococcus aureus causing invasive infections in Europe: a molecular-epidemiological analysis. PLOS Med 2010, 7:1-e1000215.

26. Rabello RF, Moreira BM, Lopes RMM, Teixeira LM, Riley LW, Castro ACD: Multilocus sequence typing of Staphylococcus aureus isolates recovered from cows with mastitis in Brazilian dairy herds. J Med Microbiol 2007, 56:1505-1511.

27. Hasman H, Moodley A, Guardabassi L, Stegger M, Skov RL, Aarestrup FM: spa type distribution in Staphylococcus aureus originating from pigs, cattle and poultry. Vet Microbiol 2010, 141:326-331.

28. Porrero MC, Hasman H, Vela Al, Fernández-Garayzábal JF, Domínguez L, Aarestrup FM: Clonal diversity of Staphylococcus aureus originating from the small ruminants goats and sheep. Vet Microbiol 2012 156:157-161.
29. Gharsa H, Ben Slama K, Lozano C, Gómez-Sanz E, Klibi N, Ben Sallem R, Gómez P, Zarazaga M, Boudabous A, Torres C: Prevalence, antibiotic resistance, virulence traits and genetic lineages of Staphylococcus aureus in healthy sheep in Tunisia. Vet Microbiol 2011, 156:367-373.

30. Almeida LM, Almeida MZ, Mendonça CL, Mamizuka EM: Novel sequence types (STs) of Staphylococcus aureus isolates causing clinical and subclinical mastitis in flocks of sheep in the northeast of brazil. J Dairy Res 2011, 78:373-378.

31. Monecke $S$, Kuhnert $P$, Hotzel H, Slickers P, Ehricht R: Microarray based study on virulence-associated genes and resistance determinants of Staphylococcus aureus isolates from cattle. Vet Microbiol 2007, 125:128-140.

32. Espinosa-Gongora C, Chrobak D, Moodley A, Bertelsen MF, Guardabassi L: Occurrence and distribution of Staphylococcus aureus lineages among zoo animals. Vet Microbiol 2012, Article in press.

33. Sung JML, Lloyd DH, Lindsay JA: Staphylococcus aureus host specificity: comparative genomics of human versus animal isolates by multi-strain microarray. Microbiol 2008, 154:1949-1959.

34. Franco A, Hasman $H$, lurescia $M$, Lorenzetti $R$, Stegger $M$, Pantosti A, Feltrin F, lanzano A, Porrero MC, Liap M, Battist A: Molecular characterization of spa type t127, sequence type 1 methicillin-resistant Staphylococcus aureus from pigs. J Antimicrob Chemother 2011, 66:1231-5.

35. McDonald M, Dougall A, Holt D, Huygens F, Oppedisano F, Giffard PM, Inman-Bamber J, Stephens AJ, Towers R, Carapetis JR, Currie BJ: Use of a single-nucleotide polymorphism genotyping system to demonstrate the unique epidemiology of methicillin-resistant Staphylococcus aureus in remote aboriginal communities. J Clin Microbiol 2006, 44:3720-3727.

36. Collery MM, Smyth DS, Twohig JM, Shore AC, Coleman DC, Smyth CJ: Molecular typing of nasal carriage isolates of Staphylococcus aureus from an Irish university student population based on toxin gene PCR, agr locus types and multiple locus, variable number tandem repeat analysis. J Med Microbiol 2008, 57:348-358.

37. Collery MM, Smyth DS, Tumilty JJG, Twohig JM, Smyth CJ: Associations between enterotoxin gene cluster types egc1, egc2 and egc3, agr types, enterotoxin and enterotoxin-like gene profiles, and molecular typing characteristics of human nasal carriage and animal isolates of Staphylococcus aureus. J Med Microbiol 2009, 58:13-25.

38. Coombs GW, Monecke S, Pearson JC, Tan H, Chew YK, Wilson L, Ehricht R, O'Brien FG, Christiansen KJ: Evolution and diversity of communityassociated methicillin-resistant Staphylococcus aureus in a geographical region. BMC Microbiol 2011, 11:215-227.

39. Argudín MA, Mendoza C, Vazquez A, Guerra B, Rodicio MR: Molecular typing of Staphylococcus aureus blood stream isolates from geriatric patients attending a long-term care Spanish hospital. J Med Microbiol 2011, 60:172-179.

40. Argudín MA, Mendoza MC, Méndez FJ, Martín MC, Guerra B, Rodicio MR: Clonal complexes and diversity of exotoxin gene profiles in methicillin-resistant and methicillin-susceptible Staphylococcus aureus isolates from patients in a Spanish Hospital. J Clin Microbiol 2009, 47:2097-2105

41. Ghasemzadeh-Moghaddama H, Ghaznavi-Rada E, Sekawia Z, Yun-Khoona L, Azizc MN, Hamata RA, Mellesd DC, Belkumd AV, Shamsudina MN, Neela V: Methicillin-susceptible Staphylococcus aureus from clinical and community sources are genetically diverse. Int J Med Microbiol 2011, 30:347-353.

42. Breurec S, Fall1 C, Pouillot R, Boisier P, Brisse S, Diene-Sarr F, Djibo S, Etienne JM, Fonkoua C, Perrier-Gros-Claude JD, Ramarokoto CE, Randrianirina FJ, Thiberge M, Zriouil SB, Garin B, Laurent F: Epidemiology of methicillin susceptible Staphylococcus aureus lineages in five major African towns: high prevalence of Panton-Valentine leukocidin genes. Clin Microbiol Infect 2010, 17:633-639.

43. Moodley A, Stegger M, Bagcigil1 AF, Baptiste KE, Loeffler A, Lloyd DH, Williams NJ, Leonard N, Abbott Y, Skov R, Guardabassi L: Spa typing of methicillin-resistant Staphylococcus aureus isolated from domestic animals and veterinary staff in the UK and Ireland. J Antimicrob Chemother 2006, 58:1118-1123.

44. Ben Slama K, Gharsa H, Klibi N, Jouini A, Lozano C, Gómez-Sanz E, Zarazaga M, Boudabous A, Torres C: Nasal carriage of Staphylococcus aureus in healthy humans with different levels of contact with animals in Tunisia: genetic lineages, methicillin resistance, and virulence factors. Eur J Clin Microbiol Infect Dis 2011, 30:499-508. 
45. Lozano C, Gómez-Sanz E, Benito D, Aspiroz C, Zarazaga M, Torres C: Staphylococcus aureus nasal carriage, virulence traits, antibiotic resistance mechanisms, and genetic lineages in healthy humans in Spain, with detection of CC398 and CC97 strains. Int J Med Microbiol 2011, 301:500-505.

46. Smyth DS, Hartigan PJ, Meaney WJ, Fitzgerald JR, Deobald CF, Bohach GA, Smyth CJ: Superantigen genes encoded by the egc cluster and SaPlbov are predominant among Staphylococcus aureus isolates from cows, goats, sheep, rabbits and poultry. J Med Microbiol 2005, 54:401-411.

47. Sobral D, Schwarz S, Bergonier D, Brisabois A, Feßler AT, Gillbert FB, Kadlec K, Lebeau B, Loisy-Hamon F, Treilles M, Pourcel C, Vergnaud G: High throughput multiple locus variable number of tandem repeat analysis (MLVA) of Staphylococcus aureus from human, animal and food sources. PLoS One 2012, 7:e33967.

48. Chen HJ, Hung WC, Tseng SP, Tsai JC, Hsueh PR, Teng LJ: Fusidic acid resistance determinants in Staphylococcus aureus clinical isolates. Antimicrob Agents Chemother 2010, 54:4985-4991.

doi:10.1186/1746-6148-8-203

Cite this article as: Gharsa et al:: High diversity of genetic lineages and virulence genes in nasal Staphylococcus aureus isolates from donkeys destined to food consumption in Tunisia with predominance of the ruminant associated CC133 lineage. BMC Veterinary Research 2012 8:203.

\section{Submit your next manuscript to BioMed Central and take full advantage of:}

- Convenient online submission

- Thorough peer review

- No space constraints or color figure charges

- Immediate publication on acceptance

- Inclusion in PubMed, CAS, Scopus and Google Scholar

- Research which is freely available for redistribution 